\title{
A study to compare the efficacy, acceptability and side effect of combined contraceptive vaginal ring with the combined oral contraceptive pills in a tertiary health centre located in central India
}

\author{
Manjari G. Jain ${ }^{1}$, Mita Mazumdar ${ }^{*}$, Neeraj K. Jain² \\ ${ }^{1}$ Department of Obstetrics and Gynecology, RKDF Medical College and Research Centre, Bhopal, Madhya Pradesh, \\ India \\ ${ }^{2}$ Department of Surgery, Atal Bihari Vajpayee Govt. Medical College, Vidisha, Madhya Pradesh, India
}

Received: 18 May 2020

Accepted: 29 June 2020

\section{*Correspondence:}

Dr. Mita Mazumdar,

E-mail: minigoel86@gmail.com

Copyright: ( ) the author(s), publisher and licensee Medip Academy. This is an open-access article distributed under the terms of the Creative Commons Attribution Non-Commercial License, which permits unrestricted non-commercial use, distribution, and reproduction in any medium, provided the original work is properly cited.

\begin{abstract}
Background: A study to compare the efficacy, acceptability and side effect of combined contraceptive vaginal ring with the combined oral contraceptive pills in a tertiary health centre (RKDF Medical College and Research Centre, Bhopal) located in central India.

Methods: This prospective randomized comparative trial enrolled hundred women aged between 20 to 40 years seeking for contraception with no contraindication to hormonal contraception. After proper counseling and informed consent, women divided into two groups, study group (50) includes women using contraceptive vaginal ring and control group (50) include women using combined oral contraceptives. The contraceptive efficacy, acceptability, tolerability and adverse events were recorded at each follow-up visit at RKDF Medical College and Research Centre, Bhopal.

Results: Vaginal ring and combined oral contraceptives were found to have comparable contraceptive efficacy. In study group no pregnancy reported during study period while one pregnancy reported in control group, which was statistically insignificant. Satisfaction, continuation and recommendation to others were more with vaginal ring which were not significant statistically. Cycle control is superior with vaginal ring. Incidence of adverse effects was same in both groups.

Conclusions: Combined contraceptive vaginal ring is an effective and reliable contraception with excellent cycle control, well-tolerated and highly acceptable to most women.
\end{abstract}

Keywords: Combined oral contraceptive pills, Contraceptive vaginal ring, Efficacy

\section{INTRODUCTION}

Contraception is the prevention of conception. Combined oral contraceptive is widely accepted and effective method of fertility control. ${ }^{1}$ Combined oral contraceptives are being used in patient of abnormal uterine bleeding. Combined oral contraceptive are associated with side effects like nausea, vomiting, breakthrough bleeding. It has disadvantages like requirement for daily administration, hepatic first pass metabolism. ${ }^{2}$ The vaginal ring is a flexible transparent ring first approved in Netherland. ${ }^{3}$ The ring contain 2.7 milligram of ethinyl estradiol and 11.7 milligram of etonogestrel. ${ }^{4}$ After insertion into vagina, it releases 120 micrograms etonogestrel and 15 microgram of ethinyl estradiol per 24 hours over a period of 3 weeks.

Its single application allows long-term dosing increase compliance and avoidance of fluctuations in hormone level decrease side effects. ${ }^{5}$ Number of randomised 
control trial have shown lower systemic ethinyl estradiol exposure, same contraceptive efficacy, superior cycle control, comparable adverse events and higher degree of satisfaction with vaginal ring as compared to combined oral contraceptives.

This study was carried out to compare contraceptive efficacy and safety of vaginal ring versus oral contraceptive pill along with acceptability of each method.

\section{METHODS}

It is prospective comparative randomized trial. The present study was conducted in department of obstetrics and gynecology, RKDF Medical College and Research Centre, Bhopal over a period of 6 month.

A total 100 cases were selected which comply with selection criteria. The study approved by research ethics committee at hospital. Informed consent was obtained from all women.

\section{Inclusion criteria}

- Women should be in age group of 20 to 40 years seeking for contraception.

\section{Exclusion criteria}

- Include known hypersensitivity to oestrogen or progestin, lactating women up to 6 months, nonlactating up to 3 months of delivery,

- Within one month of medical or surgical abortion, suspected breast malignancy, cervical malignancy, endometrial malignancy, vaginal malignancy

- History of venous thrombo embolism and cardiovascular accidents, hypertension, diabetes and liver diseases.
After proper counselling women were categorised into 2 groups with their consent.

- Group I (study group) women willing for insertion of vaginal ring

- Group 2 (control group) women willing for combined oral contraceptives.

Insertion technique: Vaginal ring is a flexible plastic ring. It is inserted in vagina between day 1 and day 5 of menstrual period and remains in place for 3 weeks. A new Ring is inserted at the end of one-week ring free interval.

Use of oral pills: Women were instructed to start taking pills from first day of menstrual cycle for 21 days.

Follow-up visits: Women of both groups were followed at 1 month, 3 months and 6 months

\section{Monitoring}

Contraceptive efficacy: It is determined by occurrence of pregnancy during study

Continuation rate: Determined by number of women report back at each follow-up.

Acceptability: Assessed by questionnaire at each followup visit.

Side effects: Monitored at each follow-up visit.

\section{RESULTS}

The present study was conducted in the department of obstetrics and gynaecology RKDF Medical College Bhopal, Madhya Pradesh, India.

Table 1: Distribution of cases according to age.

\begin{tabular}{|lllll|}
\hline Age group in years & Study group & & \multicolumn{2}{c|}{ Control group } \\
& No. of cases & Percentage & No. of cases & Percentage \\
\hline $21-25$ & 11 & $22 \%$ & 12 & $24 \%$ \\
\hline $26-30$ & 19 & $38 \%$ & 18 & $36 \%$ \\
\hline $31-35$ & 10 & $20 \%$ & 11 & $22 \%$ \\
\hline $36-40$ & 10 & $20 \%$ & 9 & $18 \%$ \\
\hline Total & 50 & $100 \%$ & 50 & $100 \%$ \\
\hline Mean \pm SD & $30.01 \pm 26.05$ & & $29.83 \pm 29.11$ & \\
\hline
\end{tabular}

Majority of women in the study group where of 26 to 30 years age group ( $38 \%$ i.e. 19 cases) followed by 21 to 25 years (22\% i.e. 11 cases) and then 31 to 35 years $(20 \%$ i.e. 10 cases) and 36 to 40 years (20\% i.e. 10 cases) (Table 1). Mean age in study group was
$30.01 \pm 26.05 y e a r s . m a j o r i t y$ of women in control were of 26 to 30 year age group (36\% i.e. 18 cases) followed by 21 to 25 years (24\% i.e. 12 cases) and followed by 31 to 35 years (22\%i.e. 11 cases) and then 36 to 40 years age group (18\% i.e. 9 cases). Mean age in combined oral contraceptive group was $29.83 \pm 29.11$ year. 
Table 2: Distribution of cases according to parity.

\begin{tabular}{|lllll|}
\hline Parity & $\begin{array}{l}\text { Study group } \\
\text { No. of cases }\end{array}$ & Percentage & Control group & No. of cases \\
\hline Nulligravida & 20 & $40 \%$ & 22 & Percentage \\
\hline Nulliparous & 24 & $48 \%$ & 23 & $44 \%$ \\
\hline Multiparous & 6 & $12 \%$ & 5 & $46 \%$ \\
\hline Total & 50 & $100 \%$ & 50 & $10 \%$ \\
\hline
\end{tabular}

Table 3: Distribution of cases according to socio-economic status. (Modified B. J. Prasad Classification).

\begin{tabular}{|lllll|}
\hline $\begin{array}{l}\text { Class (per capita income per } \\
\text { month) }\end{array}$ & $\begin{array}{l}\text { Study group } \\
\text { No. of cases }\end{array}$ & Percentage & $\begin{array}{l}\text { Control group } \\
\text { No. of cases }\end{array}$ & Percentage \\
\hline$>10000$ & 1 & $2 \%$ & - & - \\
\hline $5000-9999$ & 13 & $26 \%$ & 12 & $24 \%$ \\
\hline $3000-4999$ & 18 & $36 \%$ & 19 & $38 \%$ \\
\hline $1500-2999$ & 10 & $20 \%$ & 11 & $22 \%$ \\
\hline $500-1499$ & 8 & $16 \%$ & 7 & $14 \%$ \\
\hline$<500$ & - & - & 1 & $2 \%$ \\
\hline Total & 50 & $100 \%$ & 50 & $100 \%$ \\
\hline
\end{tabular}

Table 4: Mean body weight per assessment for study and control group.

\begin{tabular}{|lll|}
\hline Assessment & Study group mean body weight in $\mathbf{k g}$ & Control group mean body weight in $\mathbf{~ g g}$ \\
\hline Base line & 52.4 & 50.8 \\
\hline After cycle1 & 52.2 & 52.6 \\
\hline After cycle 3 & 52.1 & 52.7 \\
\hline After cycle 6 & 52.4 & 52.7 \\
\hline After cycle 9 & 52.5 & 52.9 \\
\hline After cycle 13 & 52.7 & 53.3 \\
\hline Last assessment & 52.8 & 52.8 \\
\hline
\end{tabular}

Table 5: Incidence of withdrawal bleeding in combined contraceptive vaginal ring and combined oral contraceptive treatment groups.

\begin{tabular}{|llllll|}
\hline \multirow{2}{*}{ Cycle control parameter } & Study group & \multicolumn{2}{c|}{ Control group } & p value \\
\hline Incidence of withdrawal bleeding & No. of cycle & Percentage & No. of cycle & Percentage & $>0.05$ \\
\hline $\begin{array}{l}\text { Incidence of cycle with intended bleeding } \\
\text { pattern }\end{array}$ & 643 & $99 \%$ & 637 & $98 \%$ & $<$ \\
\hline Incidence of early withdrawal bleeding & 75 & $70 \%$ & 318 & $50 \%$ & $<0.05$ \\
\hline Incidence of late withdrawal bleeding & 104 & $12 \%$ & 65 & $10 \%$ & $>0.05$ \\
\hline Incidence of irregular bleeding & 13 & $2 \%$ & 52 & $8 \%$ & $<0.05$ \\
\hline
\end{tabular}

Most of the cases in study group 48\% (24 cases) were nulliparous followed by nulligravida $40 \%$ (20 cases) and then multiparous $12 \%$ (6 cases).

Most of the cases in control group were nulliparous $46 \%$ (23 cases) followed by nulligravida 44\% (22 cases) and then multiparous $10 \%$ (five cases) (Table 2).

Maximum number of cases in study group (18 cases i.e. $36 \%$ ) and control group (19 cases i.e.38\%) belong to class III according to their social economic status. 13 cases (26\%) in study group and 12 cases (24\%) and control groups belong to class II (Table 3). 10 cases $(20 \%)$ in the study group and 11 cases $(22 \%)$ in control groups belong to class $1 \mathrm{~V} .1$ case $(2 \%)$ in study group belong to class I. 1 case (2\%) in control group belongs to class-V.

In the study group the observed mean changes in body weight was $\pm 0.4 \mathrm{~kg}$. In control group, the observed mean change in body weight was $+2 \mathrm{~kg}$. The $\mathrm{p}$ value was 0.25 which was statistically insignificant (Table 4). 
Table 6: Proportion of cases with adverse events in combined contraceptive vaginal ring and combined oral contraceptive treatment groups.

\begin{tabular}{|lllll|}
\hline Adverse events & Study group & Control group & \\
\hline Acne & No. of cases & Percentage & No. of cases & Percentage \\
\hline Breast tenderness & 1 & $1.8 \%$ & 1 & $2.5 \%$ \\
\hline Decreased libido & 2 & $4.0 \%$ & 2 & $4.1 \%$ \\
\hline Depression & 3 & $5.2 \%$ & 0 & $0 \%$ \\
\hline Device related events & 0 & $0 \%$ & 2 & $3.2 \%$ \\
\hline Headache & 1 & $2.5 \%$ & - & - \\
\hline Leucorrhoea & 1 & $2.4 \%$ & 2 & $3.3 \%$ \\
\hline Nausea & 2 & $4.2 \%$ & 1 & $2.5 \%$ \\
\hline Nervousness & 2 & $3.2 \%$ & 3 & $5.2 \%$ \\
\hline Weight gain & 1 & $2.5 \%$ & 1 & $1.6 \%$ \\
\hline Vaginitis & 1 & $1.6 \%$ & 2 & $3.3 \%$ \\
\hline Total & 2 & $4.2 \%$ & 1 & $1.7 \%$ \\
\hline
\end{tabular}

Incidence of withdrawal bleeding was 99 percent $(643$ /650 cycles) In Study group and $98 \%$ (637/650 cycles) in control group. The p-value was 0.93 which was statistical insignificant. Incidence of cycle with intended bleeding pattern was $70 \%(455 / 650$ cycles $)$ in study group and $50 \%$ (318 /650 cycles) in control group. The p-value was 0.0002 to which was statistically significant. Incidence of cycle with early withdrawal bleeding was $12 \%(78 / 650$ cycles) in study group and $10 \%$ (65/650 cycles) in control group. the p-value was 0.33 which was statistically insignificant.

Incidence of cycle late withdrawal bleeding was $16 \%$ $(104 / 650$ cycles) in study group and $22 \%(143 / 650$ cycles) in control group. The p-value was 0.02 which was statistically significant. Incidence of irregular bleeding was $2 \%$ (13/650 cycles) in study group and $8 \%(52 / 650)$ cycles in control group. The p-value was 0.0001 which was statistically significant.

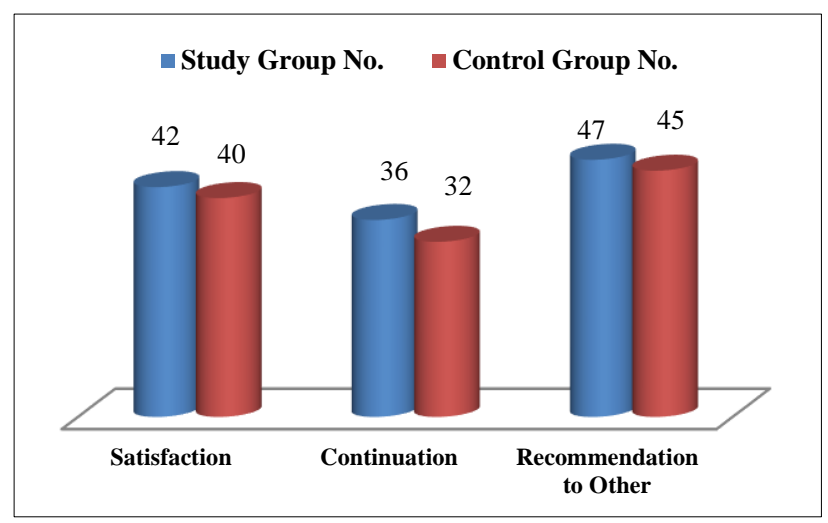

Figure 1: Distribution of cases according to the acceptability with both groups.

Satisfaction with combined contraceptive vaginal ring observed in $84 \%$ of the cases (42 cases).

Table 7: Distribution of cases according to the reason of discontinuation with combined contraceptive vaginal ring and combined oral contraceptive.

\begin{tabular}{|llllll|}
\hline \multirow{2}{*}{ Reason of discontinuation } & Study group & \multicolumn{3}{c|}{ Control group } \\
& No. of cases & Percentage & No. of cases & Percentage & p value \\
\hline Unacceptable vaginal bleeding & 1 & $2 \%$ & 1 & $2 \%$ & $>0.05$ \\
\hline Felt ring during intercourse & 2 & $4 \%$ & 0 & $0 \%$ & $<0.05$ \\
\hline No further need for contraception & 1 & $2 \%$ & 2 & $4 \%$ & $>0.05$ \\
\hline Adverse events & 6 & $12 \%$ & 6 & $12 \%$ & $>0.05$ \\
\hline Not willing to cooperate & 1 & $2 \%$ & 2 & $4 \%$ & $>0.05$ \\
\hline Others reasons & 2 & $4 \%$ & 2 & $4 \%$ & $>0.05$ \\
\hline Total & 13 & $26 \%$ & 13 & $26 \%$ & \\
\hline
\end{tabular}

Satisfaction with combined oral contraceptives observed in $80 \%$ of cases (40 cases). The p-value was 0.88 which was statistically insignificant. Continuation with combined contraceptive vaginal ring observed in $72 \%$ of 
cases (36 cases). Continuation with combined oral contraceptive observed in $64 \%$ cases (32 cases). The pvalue was 0.74 which was statistically insignificant. Recommendation of combined contraceptive vaginal ring to others observed in $94 \%$ of cases (47 cases) recommendation of combined oral contraceptive to others observed in $90 \%$ of the cases (45 cases). The p-value was 0.88 which was statistically insignificant.

In Study group, majority of women (12\% i.e. 6 cases), discontinued combined contraceptive vaginal ring because of adverse events (p-value more than 0.05) $4 \%$ of cases ( 2 cases) because of felt ring during intercourse ( $p$ value less than 0.05). $2 \%$ of cases (one case) because of unacceptable vaginal bleeding ( $p$ value more than 0.05 ) (Table 8 ). $2 \%$ of cases (one case) because they were not willing to corporate ( $\mathrm{p}$ value more than 0.05 ), $2 \%$ of cases (one case) because they had no further need for contraception and $4 \%$ of cases ( 2 cases) because of other reason ( $\mathrm{p}$ value more than 0.05 ).

In control group, majority of women (12\% i.e. 6 cases) discontinued combined oral contraceptive because of adverse events ( $p$ value more than 0.05 ). $4 \%$ of cases $(2$ cases) because of they had no further need for contraception ( $\mathrm{p}$ value less than 0.05 ). $4 \%$ of cases $(2$ cases) because they are not willing to corporate ( $p$ value more than 0.05). $2 \%$ of cases (one case) because of unacceptable vaginal bleeding ( $p$ value more than 0.05 ). $4 \%$ of cases (two cases) because of other reasons ( $p$ value more than 0.005).

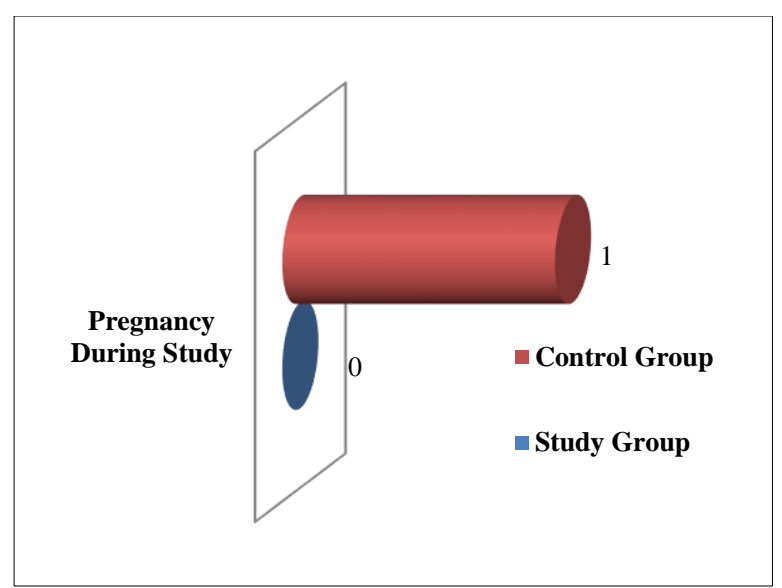

Figure 2: Pregnancy during study in both groups.

In the study group there was no pregnancy reported during study Figure 2. In the control group 1 pregnancy report during study. The $\mathrm{p}$ value was more than 0.05 which was statistical insignificant).

\section{DISCUSSION}

Total of 100 women of 20 to 40 years were subjected to detailed history, examination and relevant investigation, divided into two groups of 50 cases each. Present study conducted with aim to compare the efficacy, acceptability and side effects of vaginal ring and combined oral contraceptives.

Table 8: Comparison of incidence of adverse events in both groups with studies done by other authors.

\begin{tabular}{|lll|}
\hline Study & Pregnancy during study & Incidence of side effects \\
\hline \multirow{2}{*}{ Ahrendt et $\mathrm{al}^{7}$} & Combined contraceptive vaginal ring & $65.3 \%$ \\
\cline { 2 - 3 } & Combined oral contraceptive pills & $63.3 \%$ \\
\hline \multirow{2}{*}{ Ragnheidun et al ${ }^{6}$} & Combined contraceptive vaginal ring & $33.9 \%$ \\
\cline { 2 - 3 } In present study & Combined oral contraceptive pills & $24.6 \%$ \\
\cline { 2 - 3 } & Combined contraceptive vaginal ring & $31.6 \%$ \\
\hline
\end{tabular}

Table 9: Comparison of acceptability in both groups with studies done by other authors.

\begin{tabular}{|c|c|c|c|}
\hline Study & Pregnancy during study & Satisfaction & Recommendation \\
\hline Diben et $\mathrm{al}^{9}$ & Combined contraceptive vaginal ring & $86 \%$ & $90 \%$ \\
\hline Novak et al ${ }^{8}$ & Combined contraceptive vaginal ring & $96 \%$ & $97 \%$ \\
\hline \multirow{2}{*}{ Ahrendt et $\mathrm{al}^{7}$} & Combined contraceptive vaginal ring & $84 \%$ & $87 \%$ \\
\hline & Combined oral contraceptive pills & $87 \%$ & $92 \%$ \\
\hline \multirow[t]{2}{*}{ In present study } & Combined contraceptive vaginal ring & $82 \%$ & $94 \%$ \\
\hline & Combined oral contraceptive pills & $80 \%$ & $90 \%$ \\
\hline
\end{tabular}

Cases in both groups matched well regarding to age, parity, and social-economic status. Gain in mean weight was more with combined oral contraceptives.
No pregnancy occurred with vaginal ring and 1 pregnancy with combined oral contraceptives during study period. The difference is statistical insignificant. 
Table 10: Comparison of contraceptive efficacy in both groups with studies done by other authors.

\begin{tabular}{|c|c|c|}
\hline Study & Pregnancy during study & Pearl index \\
\hline Diben et $\mathrm{al}^{9}$ & Combined contraceptive vaginal ring & 1.75 \\
\hline \multirow{2}{*}{ Oddssonet $\mathrm{al}^{10}$} & Combined contraceptive vaginal ring & 1.23 \\
\hline & Combined oral contraceptive pills & 1.19 \\
\hline \multirow{2}{*}{ Ahrendt et al ${ }^{7}$} & Combined contraceptive vaginal ring & 0.25 \\
\hline & Combined oral contraceptive pills & 0.99 \\
\hline Soni $\mathrm{A}$ et $\mathrm{al}^{11}$ & Combined contraceptive vaginal ring & 0.0 \\
\hline \multirow{2}{*}{ In present study } & Combined contraceptive vaginal ring & 0 \\
\hline & Combined oral contraceptive pills & 2 \\
\hline
\end{tabular}

Incidence of intended withdrawal bleeding was $70 \%$ in the study group and $60 \%$ in control group. Incidence of early and late withdrawal bleeding in study group 12\% and $16 \%$ and in control group was $10 \%$ and $22 \%$. Cycle control is better in study group and difference is statistically significant.

During study period $31.6 \%$ of cases in study group and $27.4 \%$ of cases in control group developed adverse event and the differences statistically insignificant.

In study group $84 \%$ of cases satisfied with vaginal ring, $72 \%$ willing to continue, $94 \%$ recommended to others. In control group $80 \%$ of cases satisfied with combined oral contraceptives, $64 \%$ want to continue, $90 \%$ recommended it to others and difference is statistically insignificant.

\section{CONCLUSION}

This study demonstrates, on comparing vaginal ring and combined oral contraceptives, it was found that both the methods are effective as a contraceptive as studied by efficacy and acceptability.

No major side effects reported in any of the group. Combined contraceptive vaginal ring is an effective and reliable contraceptive.

No need of daily dosing further increase compliance, long term continuous release via vaginal route confer unique benefit.

Once the Government of India supplies the device free of cost as the case with combined oral contraceptive, it will have wide acceptability and may become contraceptive of choice in Indian women. However, studies with large number of cases, comparing these two methods are suggested to reach more confirmatory results.

\section{ACKNOWLEDGMENTS}

Authors would like to thank the dean, RKDF Medical College and Research Centre, Bhopal, Madhya Pradesh, India.
Funding: No funding sources

Conflict of interest: None declared

Ethical approval: The study was approved by the Institutional Ethics Committee

\section{REFERENCES}

1. Rosenberg MJ, Waugh MS. Oral contraceptive discontinuation: a prospective evaluation of frequency and reasons. Am J Obstet Gynecol. 1989;179:577-82.

2. Rosenberg M, Waugh MS. Causes and consequences of oral contraceptive non-compliance. Am J Obstet Gynecol. 1999;180:S276-9.

3. Barnhart KT, Timbers K, Pretorius ES, Link Shainik. In vivo assessment of of nuva ring placement. Contracept. 2005;72:196-9.

4. Sarkar NN. Steroidal contraceptive vaginal ring. Int J Clin Pract. 2003;57:392-5.

5. Merki Feld GS, Hund M. Clinical experience with nuva ring in daily practice in Switzerland: cycle control and acceptability among women of all. Reproductive Repord Healthcare. 2007;12:240-7.

6. Bjarnadóttir RI, Tuppurainen M, Killick SR. Comparison of cycle control with a combined contraceptive vaginal ring and oral levonorgestrel/ethinyl estradiol. Am J Obstet Gynecol. 2002;186(3):389-95.

7. Ahrendt HJ, Nisand I, Bastianelli C, Gómez MA, Gemzell-Danielsson K, Urdl W, et al. Efficacy, acceptability and tolerability of the combined contraceptive ring, NuvaRing, compared with an oral contraceptive containing $30 \mu \mathrm{g}$ of ethinyl estradiol and $3 \mathrm{mg}$ of drospirenone. Contracept. 2006;74(6):451-7.

8. Novak A, De la Loge C, Abetz L, Van der Meulen EA. The combined contraceptive vaginal ring, NuvaRing®: an international study of user acceptability. Contracept. 2003;67(3):187-94.

9. Diebenn MD, Thom OM, Frans JME. Efficacy cycle control and user acceptability of a novel combined contraceptive vaginal ring. Obstet Gynecol. 2002;100:585-93.

10. Oddsson K, Leifels-Fischer B, Wiel-Masson D, De Melo NR, Benedetto C, Verhoeven $\mathrm{CH}$, et al. 
Superior cycle control with a contraceptive vaginal ring compared with an oral contraceptive containing $30 \mu \mathrm{g}$ ethinylestradiol and $150 \mu \mathrm{g}$ levonorgestrel: a randomized trial. Human Reprod. 2005;20(2):55762.

11. Soni A, Garg S, Bangar R. Efficacy, user acceptability, tolerability, and cycle control of a combined contraceptive vaginal ring: the Indian perspective. J Obstet Gynecol India. 2013;63(5):33741.
Cite this article as: Jain MG, Mazumdar M, Jain NK. A study to compare the efficacy, acceptability and side effect of combined contraceptive vaginal ring with the combined oral contraceptive pills in a tertiary health centre located in central India. Int $\mathbf{J}$ Reprod Contracept Obstet Gynecol 2020;9:3208-14. 